\title{
GEOLOGIA, GEOQUÍMICA E MINERALIZAÇÕES AURÍFERAS DA SEQUÊNCIA MINA INGLESA, GREENSTONE BELT DE CRIXÁS, GOIÁS
}

\author{
RAUL MINAS KUYUMJIAN \& ANDRÉ LUIZ LIMA COSTA
}

\begin{abstract}
GEOLOGY, GEOCHEMISTRY AND GOLD MINERALIZATION OF THE MINA INGLESA SEQUENCE, CRIXÁS GREENSTONE BELT, GOIAS The Mina Inglesa Sequence (SMI), located in the northern part of the Crixás greenstone belt is dominantly composed by ultrabasic volcanics, and less abundant basic and intermediate volcanics, carbonaceous schist and banded iron formation, metamorphosed in the greenschist facies. This sequence constitutes the top stractigraphic unit of the Crixás greenstone. The SMI is intruded by small volumes of potassic and sodic-rich tonalites, granodiorites and granites, as well as dioritic gabbros. The close association of these granitoids with and the presence of galena and sphalerite in the sulphide paragenesis of SMI gold occurrences, and the absence of associated granitoids and galena in the other gold occurrences/deposits in the Crixás greenstone, suggest that the hydrothermal fluid responsible for the gold mineralization in the SMI, magmatic or not, passed through the granitoids leaching lead to generate galena. This and the fact that sulphides and gold from the SMI occur in veins and metamorphic segregations hosted by hydrothermally altered rocks, indicate an epigenetic hydrothermal process followed by metamorphic segregation for the generation of the SMI gold occurrences.

Keywords: Crixás Greenstone Belt, Mina Inglesa Sequence, gold.

RESUMO A Sequência Mina Inglesa (SMI), localizada na porção norte do greenstone belt de Crixás, é composta essencialmente de vulcânicas ultrabásicas e, subordinadamente, vulcânicas básicas e intermediárias, xisto carbonoso e formação ferrífera bandada, metamorfisadas na fácies xisto verde. A sequência constitui a unidade de topo do greenstone. A presença abundante de pirrotita e arsenopirita na forma de disseminações e de sulfeto maciço estratiforme no xisto carbonoso e de exalito no âmbito das ocorrências enfocadas, indicam a atuação de processo vulcanogênico-exalativo durante a deposição da SMI. Esta sequência é atravessada por corpos volumetricamente pequenos de tonalito, granodiorito e granito ricos em potássio e sódio, e de gabros dioríticos. A associação íntima de granitóides, localmente carbonatizados e com disseminações de pirita e arsenopirita, com as ocorrências auríferas no âmbito da SMI, a presença de galena na paragênese sulfetada destas ocorrências e a ausência de granitóides associados e de galena nas demais ocorrências/ depósitos de ouro do greenstone de Crixás, indicam que o fluido hidrotermal responsável pela formação da mineralização da SMI, magmático ou não, percolou as rochas granitóides, carbonatizando-as e lixiviando chumbo para a formação da galena. Este fato, e a presença de sulfetos e ouro em veios de quartzo e quartzo-carbonato e em segregações metamórficas em zona de cisalhamento direcional dextral NS superposta à SMI, favorecem um processo hidrotermal epigenético e posterior segregação e reconcentração metamórfica para a formação das ocorrências auríferas enfocadas.

Palavras-chave: Greenstone belt Crixás, Sequência Mina Inglesa, ouro.
\end{abstract}

INTRODUÇÃO O terreno arqueano da região de Crixás, Goiás, faz parte do Maciço de Goiás e é caracterizado por uma associação de complexos granito-gnáissicos estruturados em domos e uma sequência supracrustal do tipo greenstone belt, de orientação geral NS, estruturada em quilha e apresentando configuração em cúspide (Fig. 1). Este arcabouço estrutural foi gerado durante episódios tectônicos que se estenderam durante o Arqueano (Queiroz et al 1997).

O greenstone é limitado a leste pelo Complexo do Caiamar, a oeste pelo Complexo da Anta, de idades mínimas 2,5 Ma e 3,0 Ma, respectivamente (Tassinari \& Montalvão 1980), e a nordeste e a norte por rochas metassedimentares, consideradas por Pimentel et al. (1997) como pertencentes ao Arco Magmático de Goiás, de idade neoproterozóica. Os complexos consistem, predominantemente, de associações de tonalitos e granodioritos e subordinadamente granitos e trondhjemitos, atravessados por diques máficos e ultramáficos (Kuyumjian 1983, Vargas 1992). O greenstone belt de Crixás, ou
Grupo Crixás (Jost \& Oliveira 1991), compreende as Formações Córrego do Alagadinho (metakomatiitos e intercalações de formações ferríferas bandadas, xistos carbonosos, metachert e dolomitos), Rio Vermelho (metabasaltos almofadados com intercalações de xistos carbonosos) e Ribeirão das Antas (xistos carbonosos, metagrauvacas, metacherts, metaritmitos e lentes de mármore) (Saboia 1979, Kuyumjian 1981 ,Theodoro 1995). Kuyumjian (1981) considerou a atualmente denominada Sequência Mina Inglesa como uma unidade de topo do greenstone belt de Crixás, constituída essencialmente de rochas ultrabásicas talcificadas e cloritizadas e intercalações de rocha metavulcânica intermediária, formação ferrífera bandada, metachert, e xistos carbonosos, com intrusivas granitóides e gabróicas associadas. O greenstone belt de Crixás hospeda várias ocorrências/depósitos de ouro, sendo as principais as denominadas de Mina III, Mina Nova (Kuyumjian \& Dardenne 1983, Yamaoka \& Araújo 1988, Thomson 1986, Fortes 1996) e Meia Pataca (Magalhães et al. 1988, Santos \&

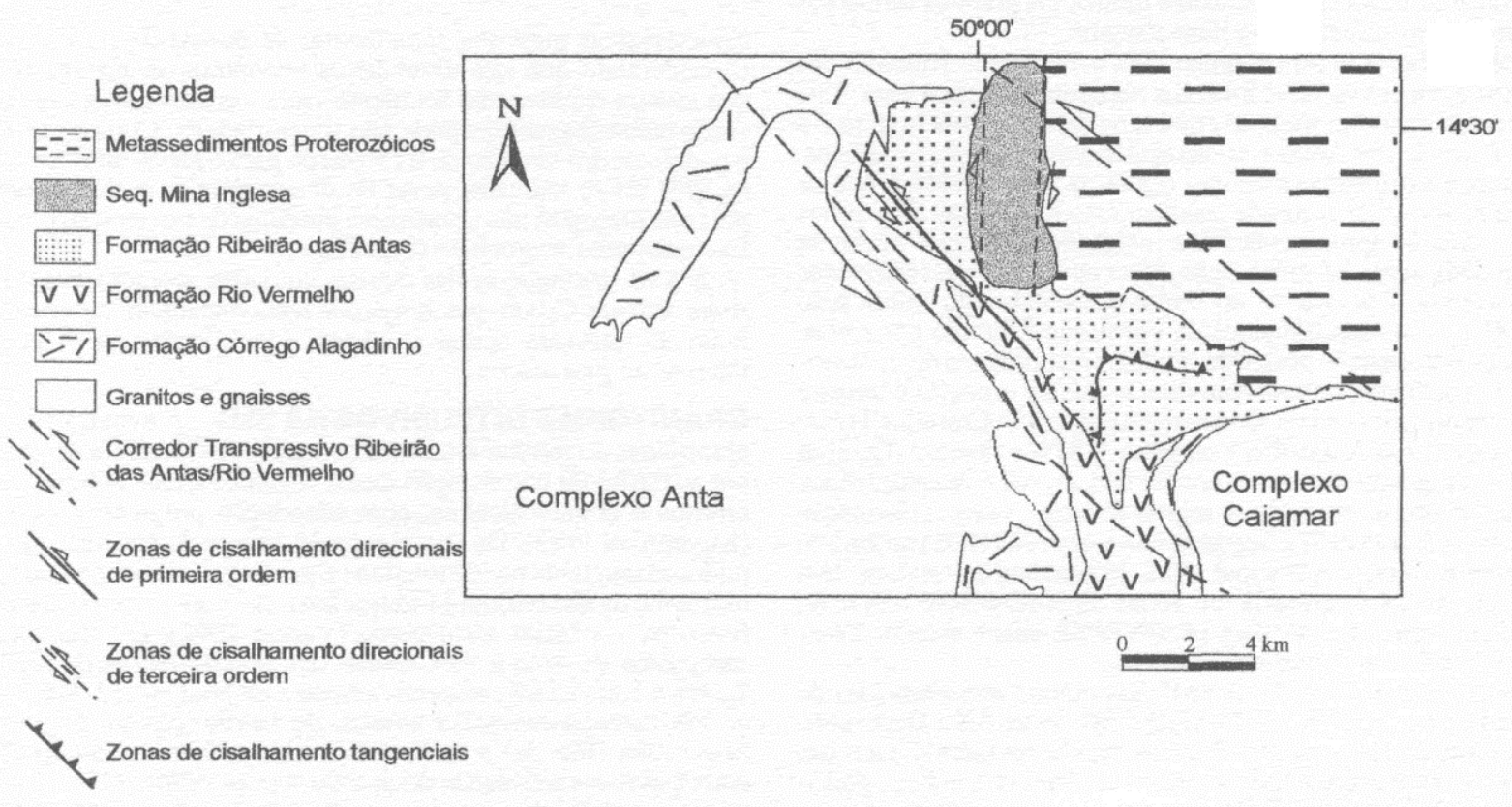

Figura l-Geologia da porção centro-norte do greenstone belt de Crixás (Queiroz 1995).

* Instituto de Geociências, Universidade de Brasília, 70910-900 Brasília, DF, E-mail: raulmk@unb.br 
Magalhães 1991, Bettencourt et al. 1991, Magalhães \& Nilson 1993) no ẩmbito da Formação Ribeirão das Antas, e Mina Inglesa, ou Chapéu do Sol, na Sequência Mina Inglesa (Kuyumiian 1981, Fortes \& Resende 1993, Fortes 1996). O depósito da Mina III ocorre em estratos constituídos por rochas metassedimentares químicas e metapelitos intercalados e, subordinadamente, metachert, metabasaltos $\mathrm{e}$ metatufos félsicos. Com relação a este depósito, Kuyumjian \& Dardenne (1983) sugerem uma origem hidrotermal exalativa e posterior segregação metamórfica em zonas axiais de dobras isoclinais, enquanto Thomson $(1986,1990)$ conclui por uma origem hidrotermal ao longo de falha de empurrão estabelecida durante o ciclo Brasiliano, e Yamaoka \& Araújo (1988) a considera como do tipo stratabound e estratiforme singenético de origem exalativa. $\mathrm{O}$ ouro está associado a sulfetos maciços e disseminados de arsenopirita, pirrotita, magnetita e, subordinadamente calcopirita. Segundo Magalhães et al. (1988) o depósito de ouro de Meia-Pataca ocorre na Unidade Grafitosa Carbonatada da Formação Ribeirão das Antas e é produto de processos exalativos e hidrotermais associados a zona de cisalhamento. Os níveis mineralizados são constituídos por pirita, arsenopirita e pirrotita, sendo que o ouro ocorre associado a estes sulfetos e também livre. Segundo Bettencourt et al. (1991) os depósitos Mina III, Mina Nova e Meia Pataca ocorrem associados a zonas de cisalhamento de baixo ângulo, confinados em nível estratigráfico preferencial, ou seja, imediatamente acima do contato entre metabásicas e metassedimentos, o que sugere uma natureza estratiforme.

O presente trabalho enfoca aspectos geológicos e geoquímicos da Sequência Mina Inglesa e as mineralizaçôes auríferas hospedadas pela mesma.

As dosagens de elementos maiores, menores e traço foram efetuadas por espectrometria de emissão de plasma (ICP) no Laboratório de Geoquímica do Instituto de Geociências-UnB, e as de elementos terras raras nos laboratórios da GEOSOL. Os dados de geocronologia foram obtidos em laboratórios da USP $(\mathrm{Rb} / \mathrm{Sr})$ e da UnB $\left.{ }^{87} \mathrm{Sr}{ }^{86} \mathrm{Sr}\right)$.

GEOLOGIA DA SEQUÊNCIA MINA INGLESA A Sequência Mina Inglesa constitui uma faixa vulcanossedimentar de, aproximadamente, $8 \mathrm{~km}$ de extensão e $2-3 \mathrm{~km}$ de largura, disposta imediatamente a noroeste de Crixás e constituída de meta vulcânicas ultrabásicas (talco xistos, clorita-talco xistos, serpentinitos e tremolita-clorita xistos), metabasaltos (epídoto anfibolitos e granada anfibolitos), metandesitos (granada-clorita-biotita-quartzo xisto, anfibólio-biotita-quartzo xisto e clorita-biotita-anfibólio-quartzo xisto, frequentemente com porfiroblástos de plagioclásio), formação ferrífera bandada; metachert e xistos carbonosos, submetidos a metamorfísmo da fácies xisto verde (Fig. 2).

Os gabros dioríticos intrusivos na SMI apresentam granulação média a grossa, essencialmente constituídos de hornblenda, diopsídio parcialmente uralitizado, plagioclásio e biotita. Os granitos intrusivos na sequência serão enfocados no item a seguir.

A sequência faz contato tectônico com a Formação Ribeirão das Antas a oeste e com os metassedimentos neoproterozóicos a leste. Tais contatos caracterizam imbricação entre a Sequência Mina Inglesa e a Formação Ribeirão das Antas e os metassedimentos neoproterozóicos, ocorrida durante o Neoproterozóico (Queiroz et al. 1995) e que se materializa na forma de zonas de cisàlhamento tangencial. Tais zonas apresentam direção aproximada NS e mergulho para oeste no limite oriental da SMI, onde há imbricação desta com os metassedimentos neoproterozóicos, e para leste no limite ocidental, com imbricação entre a SMI e os metassedimentos da Formação Ribeirão das Antas. Numa fase de deformação posterior, ainda no Neoproterozóico, desenvolveram-se zonas de cisàlhamento direcionais de primeira e terceira ordens. As de primeira ordem são caracterizadas pelo Corredor Transpressivo Ribeirão das Antas/Rio Vermelho, N50W e sinistrai (Queiroz 1995, 1997), enquanto que as de terceira ordem, NS e dextral, menos expressivas, ocorrem em toda a região (Souza 1998, informação verbal, Queiroz \& Jost 1997). Segundo Queiroz et al. (1995) no âmbito da sequência a foliação principal $(\mathrm{Sn})$, localmente milonítica, tem orientação de maior frequência em torno de N8E/44NW e N48W, 50SW, e é submetida a deflexões para NW/SE pelo Corredor Transpressivo Ribeirão das Antas/Rio Vermelho.

As rochas metaultrabásicas da SMI apresentam concentrações de $\mathrm{MgO}$ entre 18,91 e 21,77 \%, razão $\mathrm{AI}_{2} \mathrm{O} / \mathrm{TiO}_{3}$ entre 9,8 a 10,0, razão $\mathrm{Gd} / \mathrm{Yb}$ em torno de 1,49 e padrão de elementos terras raras (ETR) com fracionamento pouco acentuado e empobrecimento, também pouco acentuado, em ETR leves e ETR pesadas. Da mesma forma que os komatiitos que afloram ao longo do Córrego do Alagadinho (Formação Córrego do Alagadinho), as rochas ultrabásicas da SMI apresentam

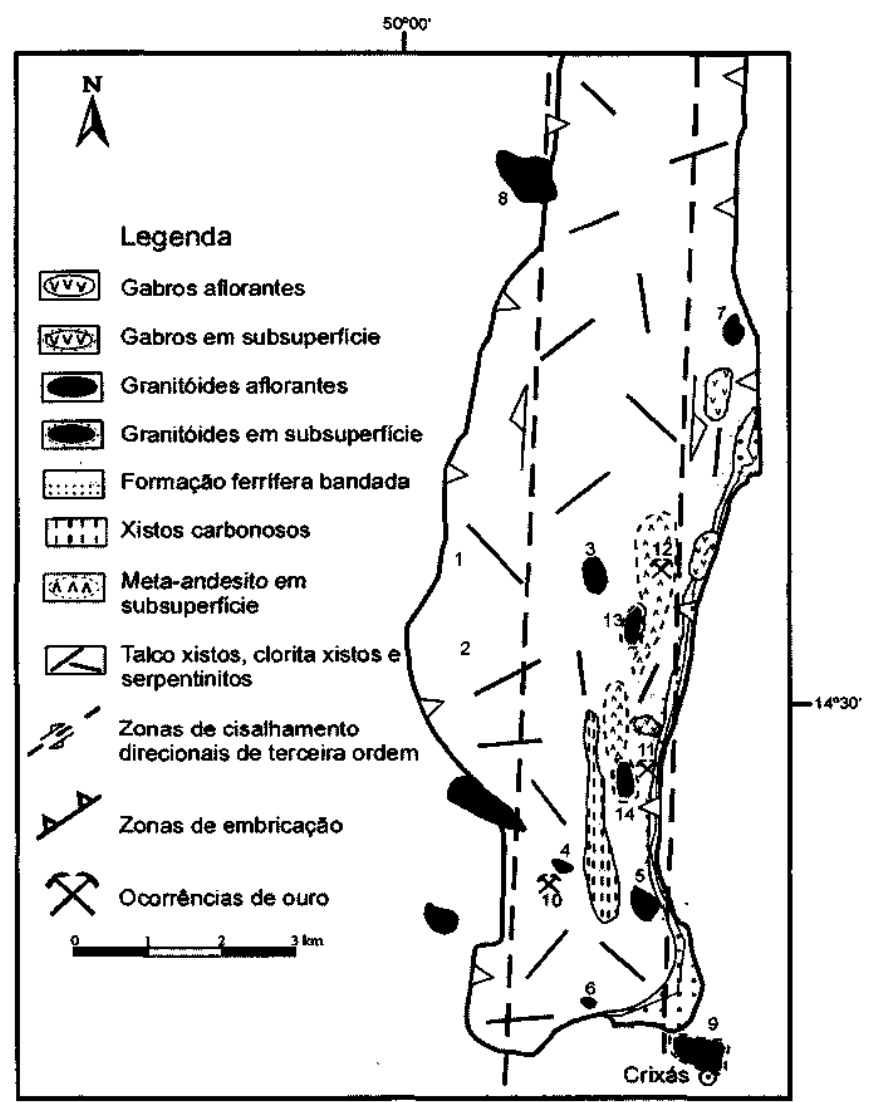

Figura - 2: Geologia da Sequência Mina Inglesa. Granitóides: l - Anta 1; 2 - Anta 2; 3 - Truvirato; 4 - Itaobi; 5 - Dona Maria; 6 - Velho Joca; 7 - Água Forte; 8 - Mumbuca; 9 - Crixás. Ocorrências de ouro: 10 - Mina Inglesa; 11 - Dona Maria; 12 - Adventino; 13 e 14 sem denominação.

características químicas semelhantes às dos Al-depleted komatiites. Considerando que tais ultrabásicas encontram-se metamorfisadas e que textura spinifex não foi identificada nas mesmas, a sua caracterização como komatiítica pode não ser verdadeira. Conforme esperado, o padrão de distribuição de ETR obtido para o gabro diorítico intrusivo na SMI difere marcantemente do obtido para as rochas ultrabásicas, pois tais litologias não constituem produtos de um mesmo processo de fracionamento magmático (Fig. 3f).

A SMI distingue-se das demais unidades supracrustais do greenstone belt de Crixás por hospedar metavulcânicas intermediárias e todas as intrusões ácidas e básicas identificadas até o presente e internas ao greenstone.

GRANITÓIDES INTRUSIVOS NA SMI A evolução das rochas granitóides do terreno arqueano da região de Crixás foi acompanhada por variação da composição desde tonalitos (mais antigos) a granodioritos e granito alcalino, com introdução progressiva de potássio (Kuyumjian 19.82). Os complexos da Anta e do Caiamar são constituídos essencialmente de tonalitos e granodioritos submetidos a metamorfismo da fácies epidoto-anfibolito a anfibolito, com retrometamorfismo para a fácies xisto verde (Vargas 1992). Os granitóides dos complexos da Anta e do Caiamar têm concentrações de $\mathrm{K}_{2} \mathrm{O}(1,13-$ $2,14 \%$ e $1,25-2,38 \%$, respectivamente), de $\mathrm{Na}_{2} \mathrm{O}(4,12-5,05 \%$ e $4,96-$ $5,37 \%$, respectivamente) e padrões de distribuicão em diagrama multielementar (Fig. 3a) semelhantes aos de granitóides do tipo TTG de outros terrenos arqueanos do mundo (Costa 1996).

Os granitóides intrusivos na Sequência Mina Inglesa (Fig. 2), podem ser divididos em quatro suites petrográfica e quimicamente distintas entre si, a seguir caracterizadas. 

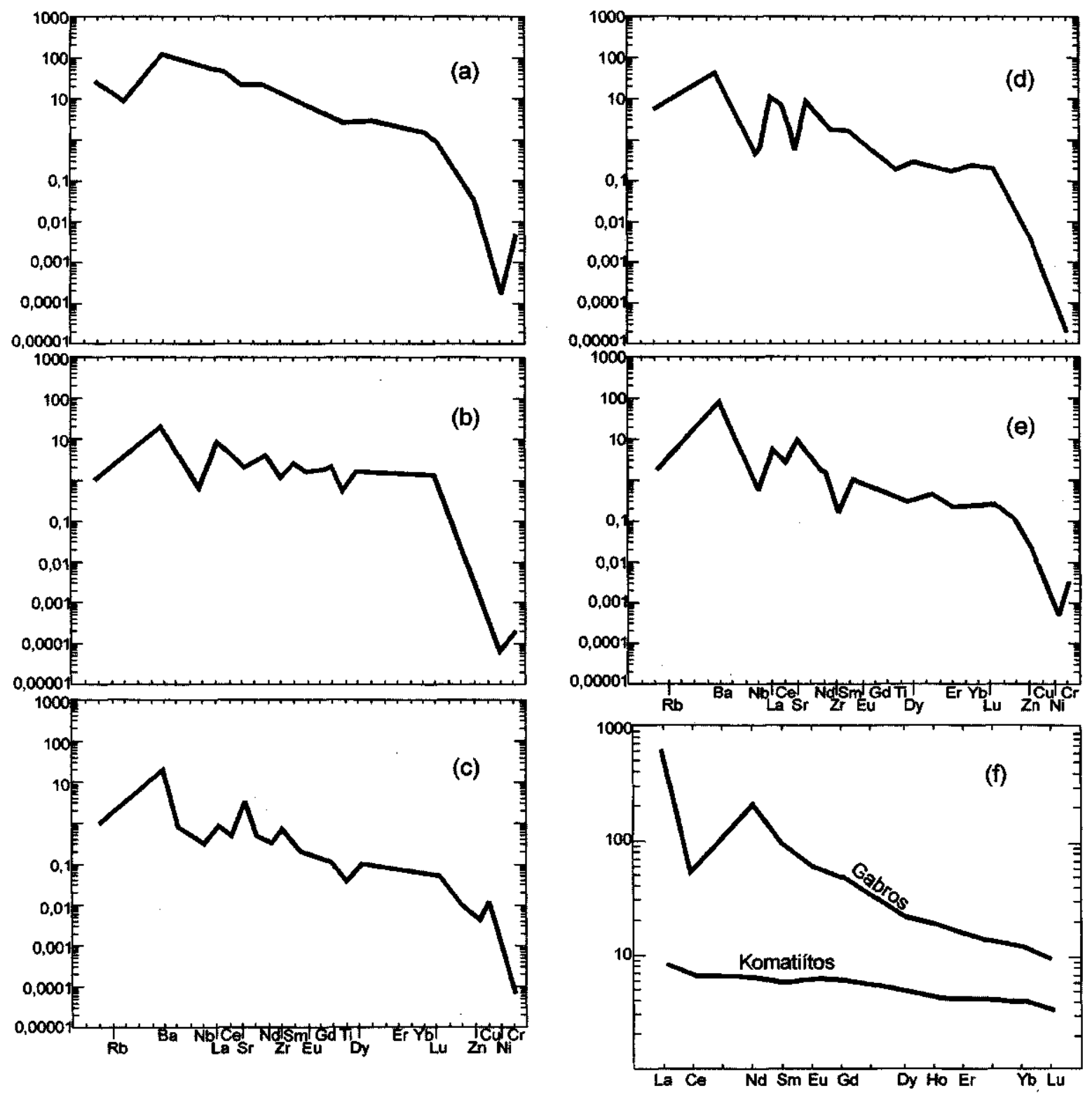

Figura 3 - Diagramas multielementares para os granitóides (a - suite 1; b - suite 2; c-suite 3; $d$-suite 4) e (f) komatiitos e gabros da Sequência Mina Inglesa.

A suite-1 compreende intrusões tonalíticas e granodioríticas cálcioalcalinas a toleiíticas com foliação metamorfica, aflorantes na porção sudoeste da sequência, constituídas essencialmente de plagioclásio, quartzo, biotita e granada, e os acessórios epídoto, carbonato e zircão, dispostos segundo texturas granoblástica e lepidoblástica. Constituem rochas meta a peraluminosas cujas principais características químicas são $\quad \mathrm{SiO}_{2}=68-70 \%, \quad \mathrm{~K}_{2} \mathrm{O}=1,57-2,41 \%, \quad \mathrm{Na}_{2} \mathrm{O}=3,78-4,63 \%$, $\mathrm{K}_{2} \mathrm{O} / \mathrm{Na}_{2} \mathrm{O}=0,35-0,60$, Zn (90-100ppm), Ba (610-1400ppm) e elementos terras raras (ETR) com padrão de distribuição horizontal para as terras raras pesadas (ETRP) e enriquecido em terras raras leves (ETRL) $(\mathrm{La} / \mathrm{Yb}=6,1-6,9)$, e pequena anomalia negativa em Eu. O padrão de distribuição multielementar (Fig. 3b) destes tonalitos é comparável ao dos plútons Flavrian e Bourlamaque da subprovíncia do Abitibi, classificados por Sutcliffe et al (1993) como pertencente a uma suite cálcio-alcalina a toleiítica pré-deformacional.

A suite-2 inclui tonalitos claros, deformados, aflorantes na porção centro-sul da sequência e constituídos por quartzo, plagioclásio, feldspato potássico, e, subordinadamente, biotita e mica branca, dispostos segundo textura granoblástica. Apresentam localmente foliação milonítica. Opacos, epídoto, zoisita e esfeno são acessórios. São rochas cálcio-alcalinas metaluminosas a peraluminosas, com concentrações de $\mathrm{SiO}_{2}=72 \%, \mathrm{~K}_{2} \mathrm{O}=0,26-0,77 \%, \mathrm{Na}_{2} \mathrm{O}=4,18-8,54 \%, \mathrm{~K}_{2} \mathrm{O} / \mathrm{Na}_{2} \mathrm{O}=$ 0,03-0,15 e baixas concentrações em Y (1-2ppm) e ETR, com padrão de distribuição fracionado, mais acentuado nos ETRL ( $\mathrm{La} / \mathrm{Yb}=8,6-13)$ e pequenas anomalias positivas e negativas em Eu. O padrão de distribuição multielementar é apresentado na Figura 3c. Tais tonalitos ocorrem intimamente associados a ocorrências auríferas na Mina Inglesa (nos garimpes Itaobí e Truvirato, na forma de apófises, e nos garimpes Adventino e Dona Maria, na forma de diques) tendo sido afetados pela alteração hidrotermal responsável pelas mineralizações auríferas da SMI e, posteriormente, milonitizados por deformação neoproterozóica.

A suite-3 compreende granitos ricos em potássio: (1) granito Mumbuca, de granulação grossa, intrusivo no limite noroeste da sequência, com deformação muito incipiente é constituído por microclínio e ortoclásio, quartzo, plagioclásio, mica branca e biotita, tendo por acessórios zircão, epídoto e zoisita. Constitui um granito peraluminoso com $\mathrm{SiO}_{2}=78 \%, \quad \mathrm{~K}_{2} \mathrm{O}=4,55-4,89 \%, \quad \mathrm{Na}_{2} \mathrm{O}=2,81-3,24 \%$, razão $\mathrm{K}_{2} \mathrm{O} / \mathrm{Na}_{2} \mathrm{O}>1$, baixas concentrações em V (1ppm), Zn (15ppm) e Sr (ISOppm), e padrão de ETR com acentuado fracionamento $(\mathrm{La} / \mathrm{Yb}=37)$ e discreta anomalia em Eu. Tais características, bem como o padrão de distribuição multielementar do granito Mumbuca (Fig. 3d) são semelhantes às da Suite Yamba (Slave Province, Canadá) (Davis et al. 1994) e da associação 3 do Norseman-Wiluna belt, Yilgarn, Austrália (Cassidy et al. 1993). Datação deste corpo pelo método $\mathrm{Rb} / \mathrm{Sr}$, gerou isócrona com idade de $1764 \pm 169$ Ma e razão inicial alta $(0.7366 \pm 0,0081)$ indicando tratar-se de um plúton evoluído e com idade correspondente ao Arqueano-Paleoproterozóico (Costa 1996); 


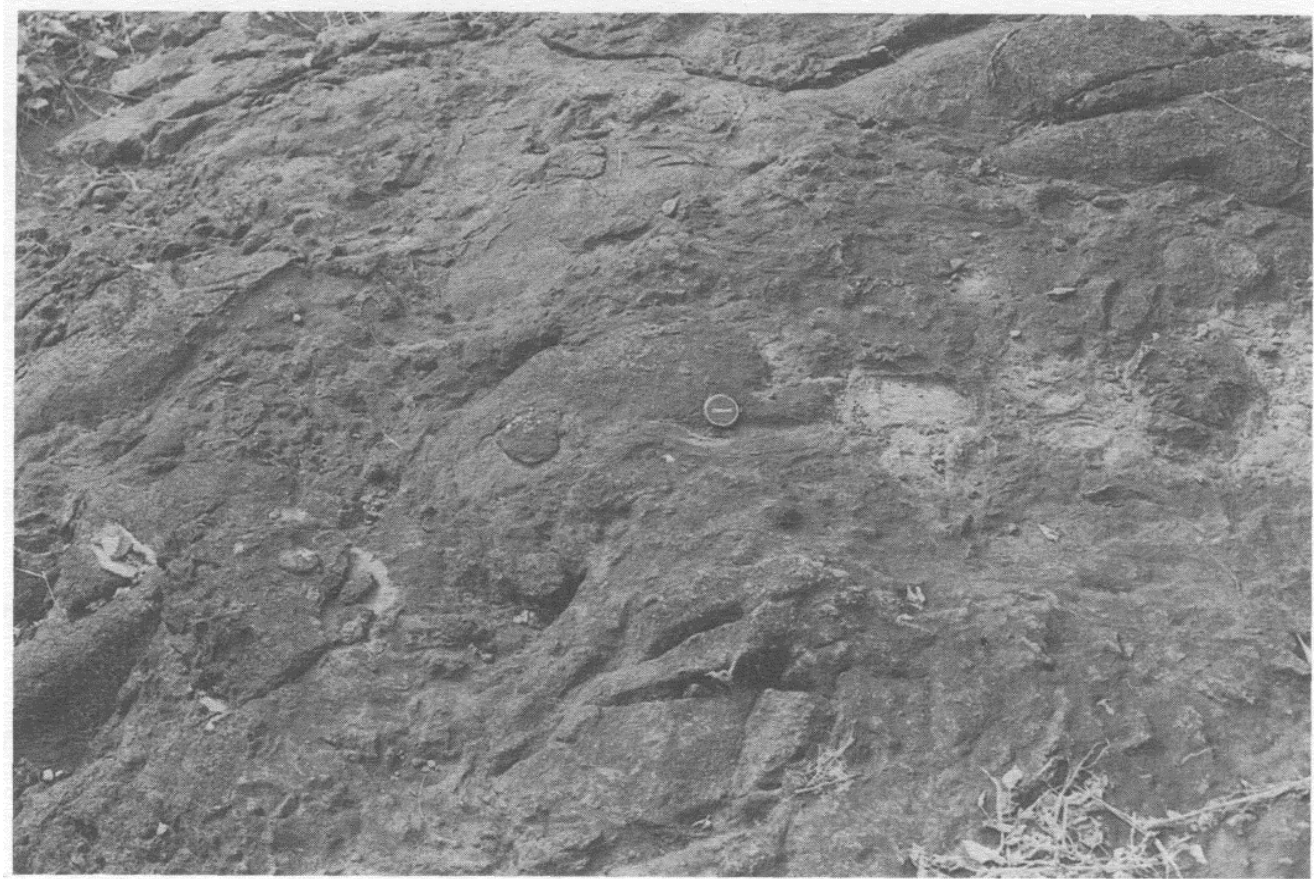

Figura 4 - Afloramento de brecha magmática granitóide da Fazenda Velho Joca.

(2) corpo de granito individualizado em subsuperfície por meio de sondagens efetuadas pela Mineração Serra Grande S.A. na cidade de Crixás. Possui granulação média-grossa, textura granoblástica e é constituído por quartzo, plagioclásio, ortoclásio, mica branca e, subordinadamente biotita. Epídoto, zoisita, zircão e apatita são acessórios. $\mathrm{A}$ análise química de uma única amostra deste granito revelou elevadas concentrações de potássio $\left(\mathrm{SiO}_{2}=70,60 \%, \quad \mathrm{~K}_{2} \mathrm{O}=5,25 \%\right.$, $\mathrm{Na}_{2} \mathrm{O}=4,18 \%, \mathrm{~K} 2 \mathrm{O} / \mathrm{Na}_{2} \mathrm{O}=1,26$ ).

A suite-4 inclui biotita tonalitos e granodioritos cálcio-alcalinos metaluminosos, de granulação grossa, ricos em epídoto, com texturas granoblástica e lepidoblástica, localmente milonítica, posicionados na porção leste e no extremo sul da sequência. A composição mineralógica essencial destas rochas inclui plagioclásio, quartzo, biotita e, muito subordinadamente, hornblenda pargasítica. Os minerais acessórios constituem zoisita, apatita e zircão. Apresentam $\mathrm{SiO}_{2}=63$ $66 \%, \quad \mathrm{~K}_{2} \mathrm{O}=1,62-2,71 \%, \quad \mathrm{Na}_{2} \mathrm{O}=4,21-5,95 \%, \quad \mathrm{~K}_{2} \mathrm{O} / \mathrm{Na}_{2} \mathrm{O}=0,27-0,64 \%$, elevadas concentrações de $\mathrm{Ba}(2000-4300 \mathrm{ppm})$ e $\mathrm{Sr}$ (865-1250ppm), padrão de distribuição de ETR mostrando acentuado fracionamento com enriquecimento em ETRL e empobrecimento em ETRP $\left[(\mathrm{La} / \mathrm{Yb})_{n}=6,6-20\right]$ e discreta ou ausente anomalia de Eu. Tais características e o padrão de distribuição multielementar destas rochas (Fig. 3e) são semelhantes às observadas por Cassidy et al. (1991) nos granitóides internos sin-deformacionais e cálcio-alcalinos da associação-1, Norseman-Wiluna belt, oeste da Austrália.

Na Fazenda Velho Joca, imediatamente a oeste da cidade de Crixás, limite sul da SMI, afloramento de aproximadamente $30 \mathrm{~m}$ de diâmetro, é constituído de brecha magmática granitóide com estruturas de fluxo preservadas (Fig. 4). A matriz da brecha constitui um actinolita-biotita granodiorito com abundância de epídoto, na qual ocorrem imersos enclaves de tonalito claros na forma de fragmentos esféricos de até $6 \mathrm{~cm}$ de diâmetro e blocos arredondados de até $50 \mathrm{~cm}$ de dimensão maior.

Com relação às composições química e mineralógica, os enclaves $\left(\mathrm{SiO}_{2}=73,60-74,97 \%, \quad \mathrm{Na}_{2} \mathrm{O}=4,07-4,67 \%, \quad \mathrm{~K}_{2} \mathrm{O}=0,54-0,90 \%\right.$ $\left.\mathrm{K}_{2} \mathrm{O} / \mathrm{Na}_{2} \mathrm{O}=0,14-0,20\right)$ se assemelham aos tonalitos da suite 2 , enquanto a matriz $\left(\mathrm{SiO}_{2}=64,05-68,26 \%, \mathrm{~K}_{2} \mathrm{O}=1,07-1,32 \%, \mathrm{Na}_{2} \mathrm{O}=2,20\right.$ $2,62 \%$ e $\left.\mathrm{K}_{2} \mathrm{O} / \mathrm{Na}_{2} \mathrm{O}=0,46-0,60\right)$ apresenta características químicas semelhantes às da suite- 4 . Se, de fato, a matriz da brecha representa uma atividade intrusiva posterior à dos tonalitos das suites 2 e 3 , a evolução das rochas granitóides com aumento progressivo de potássio e sódio, frequentemente observado em terrenos arqueanos tipo granitóide-greenstone do mundo, não se verifica em Crixás.

AS OCORRÊNCIAS AURÍFERAS N A SMI A Sequência Mina Inglesa hospeda várias ocorrências de ouro, as principais sendo as denominadas de Mina Inglesa, no limite oeste da sequência, e Adventino e Dona Maria no limite leste, nas quais se desenvolvem atividades de garimpagem (Fig. 2). Berbert \& Mello (1973) descreveram a mineralização da Mina Inglesa como consistindo de veio de quartzo com bolsões de pirita e arsenopirita encaixado em moscovita xistos e talco xistos, no interior de uma zona de cisaIhamento. Posteriormente, Berbert et al. (1980) consideraram a ocorrência como do tipo veios e filões de quartzo em zonas de cisalhamento, sugerindo controle tectono-estratigráfico e litológico. Segundo Kuyumjian \& Dardenne (1983) as principais concentrações auríferas na Mina Inglesa são produtos de soluções hidrotermais exalativas e posterior segregação, ocorrendo em barras de quartzo de 2 a $5 \mathrm{~m}$ de espessura, alojados em zona de charneira de dobras isoclinais recumbentes de eixo N30-40E em metakomatiitos talcificados e cloritizados com intercalações de metachert e xisto carbonoso. A paragênese de sulfetos inclui arsenopirita, pirita, pirrotita, galena e esfalerita, além de magnetita, hematita e ilmenita (Kuyumjian \& Dardenne 1983, Fortes e Resende 1993). Fortes (1996) evidenciou que as concentrações auríferas na Mina Inglesa ocorrem numa associação litológica incluindo talco xistos e xisto carbonoso submetidos à alteração hidrotermal dos tipos sericitização, cloritização, biotitização e, localmente, turmalinização, sendo que o corpo mineralizado constitui um veio de quartzo N30E/10-20 encaixado em talco xisto. A razão Au/Ag dos grãos de ouro em veio de quartzo na Mina Inglesa varia de 5,4 a 10,2, valores estes distintos daqueles dos depósitos das minas III e Nova, localizados a sul da faixa da SMI. Esta diferença deve-se, provavelmente à diversidade de fontes do metal em cada zona mineralizada e/ou à evolução do fluido mineralizante e/ou a reações do fluido com as rochas encaixantes e hospedeiras. Fortes (1996) mostra que a matéria carbonosa dos xistos é de origem orgânica e o fluido em inclusões do veio de quartzo mineralizado é do tipo aquoso não saturado (sistema $\mathrm{H}_{2} \mathrm{O}-\mathrm{NaCl}$ ), tipo L', sugerindo controle litológico local na sua geração. A partir do estudo em inclusões fluidas, Fortes et al (1994) e Fortes (1996a,b) obtiveram o intervalo de temperatura de 250 a $450^{\circ} \mathrm{C}$ para os fluidos precoces responsáveis pela alteração hidrotermal retrometamórfica de fácies xistos verdes associada à mineralização das minas III e Nova, enquanto que na ocorrência Mina Inglesa, o valor obtido foi de $230^{\circ} \mathrm{C}$. Segundo Fortes (1996), apesar de estágios de pré-enriquecimento singenético, assim como estágio de mobilização epigenética, não poderem ser totalmente descartados, a remobilização metamórfica foi o fator mais importante para a formação dos depósitos de ouro em Crixás. Dados geocronológicos $\mathrm{Rb} / \mathrm{Sr}, \mathrm{K} / \mathrm{Ar}$ e $\mathrm{Ar} / \mathrm{Ar}$ sugerem que o pico do metamorfismo se deu há cerca de $550 \mathrm{Ma}$, enquanto que a alteração hidrotermal e a mineralização ocorreram há $500 \mathrm{Ma}$, indicando a influência do Ciclo Brasiliano na origem das concentrações auríferas (Fortes \& Jost 1996, Fortes et al. 1997).

Os dados das ocorrências auríferas Adventino e Dona Maria obtidos até o presente consistem de observações geológicas no campo e de 


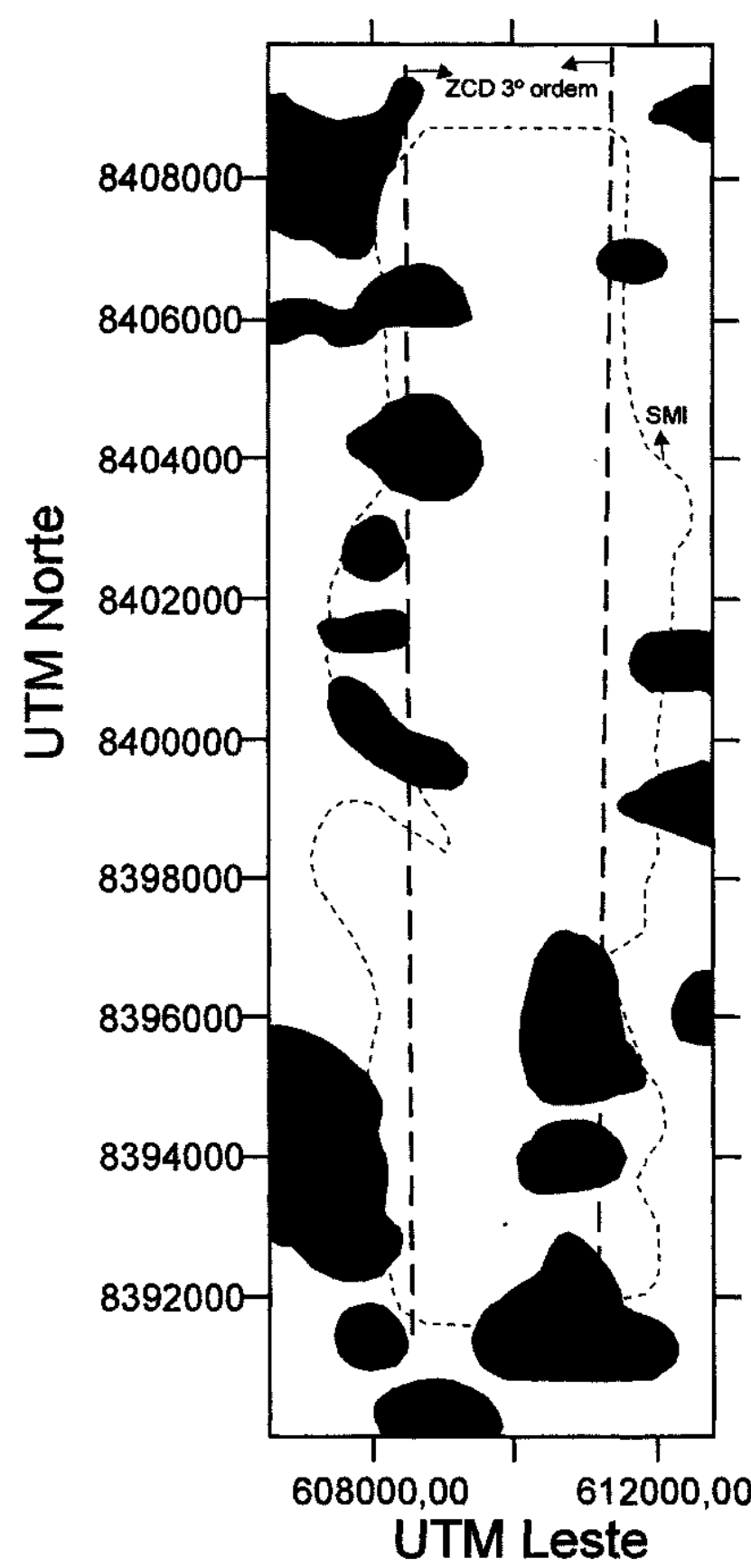

Figura 5 - Anomalias de potássio para a área da Sequência Mina Inglesa.

estudos petrográficos de testemunhos de sondagens de propriedade da Mineração Serra Grande S.A..

A ocorrência Adventino, estruturalmente controlada pela zona de cisalhamento NS, é hospedada por uma sequência de clorita xisto, clorita-carbonato xisto, clorita biotitito, biotita-carbonato xisto, turmalina-sericita xisto, anfibólio-biotita carbonato xisto e clorita actinolitito como produtos de alteração hidrotermal, além de metandesito, xisto carbonoso e um provável exalito (alternância de níveis de quartzo + carbonato com níveis de anfibólio + carbonato + opacos), litologias estas quase sempre contendo sulfetos disseminados (pirrotita, arsenopirita e calcopirita), principalmente onde sericitização e carbonatização foram mais intensas. A ocorrência Dona Maria é também controlada pela zona de cisalhamento NS e é hospedada por uma sequência de (turmalina-) sericita xisto, clorita-carbonato xisto, turmalina-carbonato-anfibólio xisto, anfibólio-carbonato xisto e talcocarbonato xisto como produtos de alteração hidrotermal e frequentemente com sulfetos disseminados (pirita, pirrotita, calcopirita e arsenopirita), além de anfibólio xisto (metabasalto), metandesitos, actinolitito e talco xisto (metaultrabásicas), xisto carbonoso e um nível pouco espesso de clorita turmalinito. Nas ocorrências Dona Maria e Adventino a sequência portadora da mineralização é atravessada por diques de tonalito com 0,5 a $3 \mathrm{~m}$ de espessura, localmente milonitizado e carbonatizado, contendo disseminações muito finas de pirita e arsenopirita e quimicamente semelhante aos tonalitos da suite-1.

As concentrações auríferas $(0,02$ a 5,05 ppm) nas duas ocorrências são hospedadas por veios de quartzo ou quartzo-carbonato em zonas de alteração hidrotermal e contendo pirita, arsenopirita, pirrotita, pentlandita, calcopirita, galena e esfalerita, e também associadas a arsenopirita, pirrotita e pirita em litologias intensamente sericitizadas e, menos frequentemente, carbonatizadas ou cloritizadas. Nos veios de quartzo o ouro ocorre incluso na arsenopirita ou no contato entre este mineral e galena, e raramente livre. As litologias com sulfetos disseminados apresentam concentrações de 235 ppm Zn e 155 ppm Cu. Rutilo, magnetita e ilmenita estão geralmente presentes em associação com os sulfetos . Na ocorrência Adventino observa-se a presença de veios de quartzo contendo sulfetos, deformados segundo dobras com eixo NS de baixo caimento e remobilizações de sulfetos e ouro para zonas de charneira. Ainda nesta ocorrência, xistos produtos de alteração hidrotermal mostram segregações metamórficas centimétricas constituídas de quartzo e sulfetos. Ao incluir galena e esfalerita na paragênese de sulfetos as ocorrências Adventino e Dona Maria contrastam com as demais ocorrências e depósitos (Mina III, Mina Nova e depósito do Meia-Pataca) do greenstone, onde a paragênese de sulfetos (pirita, arsenopirita, pirrotita e calcopirita) não inclui aqueles minerais.

O xisto carbonoso das ocorrências Adventino e Dona Maria é caracterizado pela abundância de sulfetos disseminados e níveis milimétricos a centimétricos de sulfeto maciço estratiforme. Os sulfetos constituem arsenopirita e pirrotita.

A Tabela 1 apresenta resultados de análises químicas das metavulcânicas e de xistos produtos de alteração hidrotermal das ocorrências Adventino e Dona Maria.

CONSIDERAÇÕES FINAIS Nas sequências tipo greenstone existentes no mundo o vulcanismo komatítico constitui, quase sempre, a unidade basal, e neste sentido, a Sequência Mina Inglesa, uma unidade essencialmente ultrabásica, aparentemente komatiítica, poderia estar representando uma fatia da Formação Córrego do Alagadinho posicionada tectônicamente no atual nível crustal. Assim, o posicionamento tectônico da SMI estaria representando um processo de espessamento crustal localizado, e neste caso, acompanhando modelo de England \& Thompson (1986), o gradiente geotérmico seria afetado, resultando magmatismo contemporâneo, o que explicaria a presença de granitóides internos ao greenstone quase que exclusivamente no âmbito da SMI. No entanto, considerando-se que os talco xistos e serpentinitos da SMI podem não constituir metakomatiitos, e a presença de metavulcânicas básicas e intermediárias na mesma, conclui-se que a sequência enfocada constitui uma unidade de topo do greenstone de Crixás, tal como sugerido por Kuyumjian (1981).

A evolução das rochas granitóides em terrenos tipo granitóidegreenstone belt do mundo ocorre, geralmente, com aumento progressivo de potássio e sódio, e neste sentido, os granitóides intrusivos na SMI, enriquecidos em potássio e sódio e volumetricamente menores, representam as últimas atividades da granitogênese em Crixás.

Áreas submetidas à processos de alteracão hidrotermal e possuindo expressão em superfície podem ser identificadas por meio da análise de dados gama-espectrométricos, especialmente para o canal do potássio (Pires 1995). A utilização deste método possibilitou evidenciar várias anomalias de potássio no âmbito da SMI (Fig. 4), coincidentes, muitas delas, com locais onde ocorrem, conjuntamente, intrusões granitóides, zonas de alteração hidrotermal e ocorrências auríferas ao longo de zonas de cisalhamento NS. Esta observação, e a presença de apófises e diques de rochas granitóides localmente milonitizadas e hidrotermalizadas, contendo disseminações finas de pirita e arsenopirita, em zonas de alteração hidrotermal hospedeiras das ocorrências auríferas da SMI, sugerem que tais granitóides podem ter-se constituído fator importante na génese das mineralizações auríferas daquela sequência.

A idade de $500 \mathrm{Ma}$ das mineralizações auríferas de Crixás e a de 1764 Ma (idade mínima) do granito Mumbuca, permitem conjeturar um modelo genético para as ocorrências de ouro enfocadas neste trabalho. Os granitóides intrusivos na SMI durante o Arqueano-Paleoproterozóico, particularmente os das suites 1 e 2 , constituíram a fonte dos fluidos mineralizantes, ou a fonte de calor que promoveu o fluxo de tais fluidos, magmáticos ou não. A ausência de intrusivas granitóides e gabróicas e de galena no âmbito dos depósitos Mina III, Mina 
Tabela l - Composições químicas de granitóides (l-Domo da Anta; 2-Domo do Caiamar; 3-Suite 1; 4-Suite 2; 5-Suite 3 e 6-Suite 4), gabro diorítico (7),metakomatiito (8), meta-andesito (9) e metabasalto (10) no âmbito da Sequência Mina Inglesa. Elementos maiores e menores em \% e elementos traço em ppm.

\begin{tabular}{|c|c|c|c|c|c|c|c|c|c|c|}
\hline Amosostra & 1 & 2 & 3 & 4 & 5 & 6 & 7 & 8 & 9 & 10 \\
\hline $\mathrm{SHO}_{2}$ & 76,78 & 73,52 & 70,50 & 74,60 & 78,72 & 63,20 & 52,82 & 50,60 & 32,57 & 50,60 \\
\hline $\mathrm{TOO}_{2}$ & 0,22 & 0,14 & 0,71 & 0,18 & 0,15 & 0,62 & 1,13 & 0,63 & 0,77 & 0,71 \\
\hline 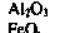 & 12,21 & 14,61 & 13,29 & 14,56 & 11,44 & 1 & $\begin{array}{r}6,63 \\
0\end{array}$ & 6.68 & 15,52 & 14,98 \\
\hline & & 1.82 & 013 & 00 & & & 12,80 & $\begin{array}{ll}10,34 \\
0.14\end{array}$ & & 015 \\
\hline $\mathrm{MgO}$ & 0,63 & 0,52 & 1,13 & 1,05 & 0,37 & $\begin{array}{l}0,30 \\
3,30\end{array}$ & $\begin{array}{l}10,52 \\
\end{array}$ & 21,77 & .6.48 & 9,07 \\
\hline $0 \infty$ & 1,86 & $\begin{array}{l}2.73 \\
5,37\end{array}$ & 1,95 & 1,70 & 0,40 & 4.17 & 14,06 & 8.83 & 6.74 & 8,45 \\
\hline & 2,82 & 5,37 & 3,78 & s.16 & , 306 & 5,61 & 0,82 & $\begin{array}{l}0.58 \\
0.8\end{array}$ & $\begin{array}{l}2.58 \\
.258\end{array}$ & 1,36 \\
\hline & , & $0 \infty$ & 0 & 0.12 & 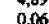 & 03 & 0,45 & 0 & 1006 & \\
\hline $\mathrm{PF}$ & 0,42 & 1,41 & 0,81 & 0,59 & 0,63 & 2,00 & 2,81 & 7,709 & 3,74 & 2,37 \\
\hline a & 25 & 1 & - & $=$ & - & 122 & 441 & 1625 & 38 & 475 \\
\hline $\begin{array}{l}\mathrm{Ni} \\
\mathrm{Co}\end{array}$ & $133^{2}$ & $\frac{1}{77}$ & 120 & 76 & 153 & $\begin{array}{l}355 \\
68\end{array}$ & $\begin{array}{r}268 \\
131\end{array}$ & $\begin{array}{l}921 \\
135\end{array}$ & 57 & 166 \\
\hline v & 26 & 21 & 4 & 16 & & 100 & 228 & 163 & & 261 \\
\hline Ba & 11119 & 533 & 1410 & 1006 & 1600 & 3900 & 216 & 18 & 284 & 1230 \\
\hline $\begin{array}{l}\text { Sr } \\
\text { Nbb }\end{array}$ & & 408 & $\begin{array}{r}180 \\
2\end{array}$ & 400 & $\begin{array}{r}60 \\
2\end{array}$ & 1200 & 330 & 77 & 150 & 460 \\
\hline$z r$ & 69 & 87 & 62 & i & 88 & $i$ & 45 & 31 & 47 & 42 \\
\hline 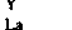 & 29.77 & 25.40 & 45 & 1 & 4572 & 13 & $\begin{array}{r}35 \\
197\end{array}$ & 9 & & \\
\hline $\overrightarrow{\mathrm{Ce}}$ & 45,50 & 42.31 & 65.30 & 4,80 & 74,20 & 43,90 & 43,9 & $\begin{array}{l}2,02 \\
5,95\end{array}$ & . & . \\
\hline Sm & 2,088 & $\begin{array}{l}3,52 \\
16009\end{array}$ & 7,08 & 0.43 & $\begin{array}{l}4,35 \\
3820\end{array}$ & $\begin{array}{r}3,60 \\
19,10\end{array}$ & 19,9 & 1,21 & $\therefore$ & : \\
\hline Eu & 0,59 & 1,00 & 1,88 & 0,18 & 1,00 & 1,00 & 4,58 & 0,51 & . & . \\
\hline Gd & 1,36 & 3,25 & 6,72 & 0,50 & 256 & 3,13 & 13,39 & 1.72 & & \\
\hline Dy & 0,82 & 2.68 & 6.94 & 0.36 & 1.18 & 2.27 & 7.56 & 1,77 & - & - \\
\hline $\begin{array}{l}B^{B 0} \\
E_{r}\end{array}$ & $\begin{array}{l}0.15 \\
0.30\end{array}$ & $\begin{array}{l}0,92 \\
1,31\end{array}$ & $\begin{array}{l}1,4 r \\
4,23\end{array}$ & $\begin{array}{l}0,06 \\
0,14\end{array}$ & $\begin{array}{l}0,213 \\
0,54\end{array}$ & $\begin{array}{l}0,4+1 \\
1,16\end{array}$ & $\begin{array}{l}1,47 \\
3,53\end{array}$ & $\begin{array}{l}0,33 \\
1,00\end{array}$ & . & 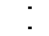 \\
\hline 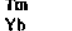 & 0.36 & 0,86 & 4,46 & 0.14 & 0.53 & $i \infty 0$ & 277 & 0,92 & : & : \\
\hline & 0.07 & 0.1 & 0.53 & 0,02 & 0.08 & 0.13 & 0,34 & 0.12 & & . \\
\hline
\end{tabular}

Nova e do Meia Pataca, localizados fora dos limites da Sequência Mina Inglesa, e a presença das mesmas nesta sequência, sugerem que o fluido hidrotermal responsável pela mineralização aurífera na SMI percolou os granitóides, carbonatizando-os e lixiviando chumbo para a formação da galena. É interessante notar que galena faz parte das paragêneses de sulfetos dos depósitos auríferos Maria Lázara (greenstone de Guarinos), Ogó (greenstone de Pilar de Goiás) (Pulz 1995) e Vira-Saia (greenstone do Tocantins, região de Almas) (Cruz 1993) intimamente associados a intrusões granitóides, enquanto que aquele mineral é ausente na paragênese sulfetada do depósito do Paiol, município de Almas, TO (greenstone do Tocantins), hospedado por metabasaltos hidrotermalizados e onde, aparentemente, não existem intrusivas granitóides associadas.

Embora a existência de xisto carbonoso rico em pirrotita e arsenopirita, por vezes na forma de sulfeto maciço estratiforme , e de prováveis exalitos na sequência de rochas das ocorrências Mina Inglesa, Dona Maria e Adventino, indiquem a atuação de processo vulcanogênico-exalativo durante a deposição da SMI, a presença de sulfetos e ouro em veios e segregações metamórficas no âmbito de rochas hidrotermalizadas favorece um processo hidrotermal epigenético e posterior segregação metamórfica para a formação das mineralizações enfocadas. De qualquer forma, a tectônica (neoproterozóica?) que afetou a SMI e intrusivas associadas promoveu segregação metamórfica e reconcentração de sulfetos e ouro de origem hidrotermal, e possivelmente vulcanogênico-exalativo, ao longo de zona de cisalhamento direcional dextral NS.

Agradecimentos Ao CNPq (processo 520433/96-3) e à Mineração Serra Grande S. A. pelo suporte à realização do presente trabalho, aos geólogos Walter N. Yamaoka e Leonardo H. de Souza, da Mineração Serra Grande S.A., pelas discussões sobre vários aspectos geológicos durante as etapas de campo, e aos pesquisadores Márcio Martins Pimentel, do Instituto de Geociências daUnB, e Colombo C.G. Tassinari, do Instituto de Geociências da USP, por possibilitar a obtenção de dados geocronológicos. A dois revisores anónimos da RBG pelas sugestões e críticas.

\section{Referências}

Berbert C.O. \& Mello J.C.R. 1973. Notas sobre a ocorrência de ouro na região de Crixás (GO). In: SBG, Congr. Brás. Geol., 27, Aracaju, Anais, 164-179.

Berbert C.O, Olivatti O., Correia Filho F.C.L., Oliveira C.C. 1980. Controles de mineralização aurífera no Centro-Oeste Brasileiro. In: SBG, Congr. Brás. Geol., 31, Camboriú, Anais, 3:1388-1401

Bettencourt J.S., Costa R.R., Souza L.H. de, Matos T.T. de. 1991. Controls of gold mineralization in the Córrego Geral sector, north central section of lhe Crixás greenstone belt: a preliminary report. In: Brazil Gold'91, Belo Horizonte, Proceedings, 699-703.

Cassidy K.F., Barley M.E., Groves D.I., Perring C.S., Hallberg J.A. 1991. An orverview of the nature, distribution and inferred tectonic setting of granitoids in the late-Archaean Norseman-Wiluna Belt. Precambrian Research, 51:51-83.

Costa A.L.L. 1996. Sequência Mina Inglesa: caracterização química das rochas granitóides associadas, Crixás, Goiás. Instituto de Geociências, Universidade de Brasília, Brasília, Dissertação de Mestrado, $88 \mathrm{p}$

Cruz E.L.C.C. 1993. Geologia e mineralizações auriferas do terreno granitóide-greenstone de Almas-Dianónopolis, Tocantins. Instituto de Geociências, Universidade de Brasília, Dissertação de Mestrado, 152p.

Davis W.J., Fryer B.J., King J.E. 1994. Geochemistry and evolution of Late Archaean plutonism and its significance to the tectonic development of the Slave craton. Precambrian Research, 67:207-241

England P.C. \& Thompson A.B. 1986. Some thermal and tectonic models for crustal melting in continental collision zones. In M.P. Coward \& A.C. Ries (eds) Collision Tectonics. Geological Society of America Special Publication 19,158-173.

Fortes P.T.F.O., Cheilletz A., Giuliani G., Féraud G. 1997. A Brasiliano age (500 \pm 5 Ma) for the Mina III gold deposit, Crixás greenstone belt, central Brazil. Intern. Geol. Rev., 39:449-460.

Fortes P.T.F.O., Giuliani G., Coelho R.F. 1994. Estudo de inclusões fluidas associadas ao veio de quartzo mineralizado do depósito aurífero Mina III, Crixás, GO. SBG/Núcleo Centro-Oeste, Boletim de Geociências do Centro-Oeste, 17(1/2):13-19.

Fortes P.T.F.O. \& Jost H. 1996. Metallogeny of Mina III, Mina Nova and Mina Inglesa gold deposits, Crixás greenstone belt, central Brazil. In: SBG, Simp. Archaean Terranes South American Platform, Brasília, Extended Abstracts, 18-19.

Fortes P.T.F. \& Resende L. 1993. Nota preliminar do depósito aurífero Mina Inglesa, Crixás, GO. SBG/ Núcleo Centro-Oeste, Boletim Informativo, 16:145-156.

Jost H. \& Oliveira A.M. 1991 Stratigraphy of the greenstone belts, Crixás region, Goiás, central Brazil. Journ. South. Amer. Earth Scienc., 4(3):201-214.

Kuyumjian R.M. 1981. Geologia e mineralizações auriferas do greenstone belt da Faixa Crixás, $G O$. Instituto de Geociências, Universidade de Brasília, Brasília, Dissertação de Mestrado, $67 \mathrm{p}$.

Kuyumjian R.M. 1982. Caracterização geoquímica preliminar das rochas graníticas associadas ao greenstone belt da Faixa Crixás, GO. SBG/ Núcleo Centro-Oeste, Boletim Informativo 11:23-29.

Kuyumjian R.M. \& Dardenne M.A. 1983.0 controle das mineralizações auríferas do greenstone belt da Faixa Crixás, GO. In: SBG-Núcleo Bahia/CBPM, Simpósio mineralizações auríferas no Estado da Bahia, Anais, 56-59.

Magalhães L.F., Lobo R.L.M., Botelho L.C.A., Pereira R.C. 1988. Depósito de ouro de Meia-Pataca, Crixás, Goiás. In: Principais depósitos minerais do Brasil, Brasília, DNPM/CVRD, volume 3, p.499-522.
Magalhães L.F. \& Nilson A.A. 1993. Controle lito-estrutural e características da mineralização aurífera da região do Córrego Geral - Meia Pataca, Crixás, GO. SBG/Núcleo Centro-Oeste, Boletim Informativo, 16:25-50.

Pimentel M.M., Whitehouse M.J., Viana M.G., Fuck R.A., Machado N. 1997. The Mara Rosa Are in the Tocantins Province: further evidence for Neoproterozoic crustal accretion in Central Brazil. Precamb. Rés., 81:299-310.

Pires A.C.B. 1995. Identificação geofísica de áreas de alteração hidrotermal, Crixás-Guarinos, Goiás. Rev. Brás. Geoc., 25(1):61 -68.

Pulz G.M. 1995. Modelos prospectivos para ouro em greenstone belts: exemplo dos depósitos Maria Lázara e Ogó, na região de Guarinos e Pilar de Goiás, Goiás. Instituto de Geociências, Universidade de Brasília, Brasília, Tese de Doutoramento, $190 \mathrm{p}$.

Queiroz C.L. de. 1995. Caracterização dos domínios estruturais e da arquitetura do greenstone belt de Crixás, GO. Instituto de Geociências, Universidade de Brasília, Brasília, Dissertação de Mestrado, $117 \mathrm{p}$.

Queiroz C.L. de, Alkmim F.F., Kuyumjian R.M. 1995. Estudo dos lineamentos de relevo da região do greenstone belt de Crixás, GO, através de imagens de sensores remotos. SBG/Núcleo Centro-Oeste, Boletim de Geociências do Centro-Oeste, 18 (1/2):57-65.

Queiroz C.L. \& Jost H. 1997. Arcabouço tectono/estrutural dos terrenos gianiio-greenstone belt de Crixás e Guarinos(GO): integração do conhecimento adquirido. In: SBG-Núcleo Brasília/UnB, VI Simpósio Nacional Estudos Tectônicos, Anais, 23-26.

Saboia L.A. de. 1979. Os greenstone belts de Crixás e Goiás, GO. SBG/Núcleo Centro-Oeste, Boletim Informativo, 9:44-72.

Santos M.M.dos \& Magalhães L.F. 1991. Geologia da Região do depósito aurífero Meia Pataca. SBG/Núcleo Centro-Oeste., Boletim Informativo, 14:91-107

Souza L.H. de. 1992. Greenstone belt de Crixás - Depósito de ouro Mina III, Crixás, Goiás. Mineração Serra Grande S.A. (inédita). 25p.

Sutcliffe R.H., Barrie C.T., Burrows D.R., Beakhouse G.P. 1993. Plutonism in the Southern Abitibi Subprovince: a tectonic e petrogenetic framework. Economic Geology, 88:1359-1375.

Tassinari C.C.G. \& Montalvão R.M.G. 1980. Estudo Geocronológico do Greenstone Belt de Crixás In: Congresso Brasileiro de Geologia, 31, Goiânia, 1980. Anais...Goiânia, SBG. V. 5, P. 2752- 2759 .

TheodoroS.C. 1995. Ambiente de sedimentação da Formação Ribeirão das Antas, Grupo Crixás, Goiás. Instituto de Geociências, Universidade de Brasília, Brasília, Dissertação de Mestrado, $88 \mathrm{p}$.

Thomson M.L. 1986. Petrology of the Crixás gold deposit, Brazil - Evidence for gold associated with hidrotermal alteration, subsequent to metamorphism. In: An International Symposium Geology Gold Deposits - Gold'86, Proceedings, 284-296.

Thomson M.L. \& Fyfe W.S. 1990. The Crixás gold deposit, Brazil: thrust-related postpeak metamorphic gold mineralization of possible Brasiliano Cycle. Econ. Geol.: 85:928-942.

Yamaoka W.N. \& Araújo E.M. 1988. Depósito de ouro de Mina III, Crixás, Goiás. In: Principais depósitos minerais do Brasil, Brasilia, DNPM/CVRD, vol. 3, p. 491-498.

Manuscrito A-1008

Recebido em 16 de julho de 1998

Revisão dos autores em 10 de agosto de 1999

Revisão aceita em 15 de agosto de 1999 